\title{
Impact of Achieved Tenure and Promotion on Faculty Research Productivity at a School of Pharmacy
}

David M. Scott, BPharm, MPH, PhD; Michael P. Kelsch, PharmD; Daniel L. Friesner, PhD

School of Pharmacy, College of Health Profession, North Dakota State University

\begin{abstract}
Objective: Critics of the promotion and tenure system contend that promotion and tenure may lead to a decline in research productivity ("dead wood phenomena") by those faculty. To assess this perception, we compiled the publications and grants at the time of application for promotion, and again through 2017 for the same faculty following promotion and/or tenure.

Methods: Promotion documents at a school of pharmacy at a public Midwestern university were assessed. Mean publication rates and grant dollars per year per faculty member were compared to the same group of faculty ( $n=13)$ pre and post-promotion.

Results: At the time of promotion to associate professor, mean numbers of total publications per year per faculty in the pharmacy practice department were 1.1, compared to 1.4 post-promotion. For pharmaceutical sciences department faculty, corresponding means were 5.0 and 4.1, respectively. At the time of promotion to full professor, mean numbers of total publications per year for pharmacy practice faculty were 7.0, compared to 7.2 post-promotion. For pharmaceutical sciences faculty, corresponding means were 3.5 and 4.7, respectively. For grant activity, both associate professors and full professors increased the mean total dollars per year from prepromotion to post-promotion for both departments.

Conclusion: Research productivity at this school of pharmacy continues to be either maintained or increased since promotion for the collective group of faculty. This evidence runs counter to the perception that promotion and tenure may lead to decreased scholarly productivity. The study provides a roadmap for other schools/colleges to quantify research productivity and make comparisons to national mean levels reported in the literature.
\end{abstract}

Keywords: Productivity, Scholarship, Publication Rates, Promotion and Tenure, Grants

\section{Introduction}

The promotion and tenure process is one of the most prominent, outcome-oriented, aspects of faculty development. Achieving tenure and promotion is a signal that an individual has continued success in all areas of academic practice, including teaching, scholarship, and service. ${ }^{1-3}$ Negative perceptions about the tenure and promotion process are prevalent in academia. ${ }^{4-7}$ One perception is that, once a faculty member achieves tenure and/or promotion, he/she experiences a perverse incentive to decrease his/her efforts in one or more areas of academic work. ${ }^{4-6}$ However, such perceptions largely anecdotal, and little systematic evidence exists to substantiate whether these assertions are pervasive or idiosyncratic. Scholarship may receive more weight than teaching and service activities in the promotion and tenure process because the outcomes of research/scholarship (grants, journal articles, etc.) are more easily quantified. ${ }^{7}$

Corresponding author: David M. Scott, BPharm, MPH, PhD Professor of Pharmacy Practice

School of Pharmacy, College of Health Profession

North Dakota State University, Fargo, ND 58104-6050

Phone: (701)231-5867; Email: david.scott@ndsu.edu
Scholarship, defined as the generation, advancement, or transformation of knowledge within a discipline, is primarily, albeit not exclusively, communicated through peer-reviewed publications. ${ }^{1}$ Within academic pharmacy, full-time faculty members (whether or not they are in tenure-track positions) are typically expected to build and maintain a continued record of scholarship for promotion and/or tenure. Given the need to balance scholarship expectations with teaching and service responsibilities, some faculty consider this to be a daunting challenge. $^{2}$

Colleges and schools of pharmacy are made up of both practicing clinicians/clinical scholars, and traditional academic/basic research faculty. The former typically populate departments of pharmacy practice, while the latter typically populate departments of pharmaceutical sciences (and, departments of social and administrative pharmacy). Faculty in departments of pharmacy practice often have a workload consisting of traditional didactic teaching responsibilities, experiential teaching responsibilities, and service commitments, in addition to scholarly activities. ${ }^{3}$ Concomitantly, pharmaceutical and social/administrative sciences faculty typically have greater scholarship demands compared with those in pharmacy practice departments, with fewer, or no, experiential teaching responsibilities. Moreover, those experiential teaching responsibilities that pharmaceutical and social/administrative sciences faculty do have (i.e., mentoring masters students, Ph.D. 
students, and Pharm.D. students interested in research careers) often aligns with, and supports the creation of scholarly output.

Given these competing demands for a typical faculty member's time, a line of research exists that attempts to empirically characterize scholarly output, relative to their other duties. In 2007, Coleman and Schlesselman reported that $4.9 \%$ of pharmacy practice faculty members published an average of 2 or more publications per year, $2.3 \%$ had published an average of 3 or more; and $1.1 \%$ had averaged 4 or more. ${ }^{8}$ Chisholm-Burns and Spivey reported that over a 5-year study period (2006-2010), public pharmacy colleges (14.6) had more total publications per faculty member than did private institutions (5.9)..$^{9}$ Moreover, pharmacy practice faculty (who are not affiliated with social/administrative sciences positions) reported publishing an average of 0.5 articles per year.9 Weathers and Unni assessed the publication rates from 2011 through 2015 in non-research intensive pharmacy schools, finding that the average number of publications was 0.92 per year for social/administrative science faculty, compared to 0.82 for other pharmaceutical sciences. ${ }^{10}$ Thompson and Nahata reported much higher average faculty publication rates during the 2006-2010 time period for pharmaceutical sciences faculty members at schools they designated as research-intensive; ${ }^{11}$ a finding consistent with other studies. ${ }^{12,13}$ Thompson and Harrison reported that $10 \%$ of pharmaceutical sciences faculty members at research-intensive schools contributed $50 \%$ of their publications. ${ }^{14}$

While the literature describes stark contrasts in scholarly output between pharmacy practice and other (pharmaceutical sciences and social/administrative pharmacy) faculty working in colleges and schools of pharmacy, it omits a crucial policy issue; namely, the unintended effects of promotion and tenure. Critics of the tenure system in higher education often assert that once faculty are tenured and/or promoted (especially to the rank of full professor), the incentives to maintain previous levels of scholarly productivity declines, called the "dead wood phenomena". ${ }^{4-6}$ If senior and/or tenured faculty are less research productive, but enjoy greater salaries and job security than less senior faculty, there is an inequitable redistribution of institutional resources to these faculty. ${ }^{7}$ Moreover, the Thompson and Harrison study suggests that department-level publication statistics may mask the dead wood phenomena, especially if the department houses a small number of prolific scholars. ${ }^{14}$ Instead, scholarship must be examined across faculty ranks within a department.

The goal of this single site study with an observational design is to empirically assess whether scholarly activity (publications, grants) increases, decreases, or remains the same following tenure and/or promotion at a school of pharmacy. The authors compiled counts of publications and grants at the time of application for promotion (starting in 2008), and the number publications and grants through the end of the 2017 calendar year for the same group of promoted faculty, and subsequently compare these counts to each other, as well as to published national estimates.

\section{Methods}

Study Site Description

This study was conducted at one school of pharmacy contained within a public university in the Midwestern U.S. from 20082017. This school of pharmacy is contained within a larger college of health professions, which offers a variety of professional clinical training programs. The college is not an academic health center since it does not house a medical school or a teaching hospital. The school of pharmacy is comprised of two departments: a department of pharmaceutical sciences (12 faculty spanning all basic sciences relevant to the school, including pharmaceutics, pharmacology, kinetics, etc.), and a department of pharmacy practice (24 faculty who are either clinical or social/administrative sciences faculty). Weathers and Unni criteria classified this school as a non-research intensive institution. ${ }^{10}$ The school offers both the Pharm.D. degree and a Ph.D. in pharmaceutical sciences, and enrolls approximately 340 and 50 students in each program, respectively. The school also offers a number of joint degrees, including Pharm.D./M.B.A., Pharm.D./M.P.H. and Pharm.D./Ph.D.

Conducting this assessment within a single school of pharmacy exhibits several advantages consistent with a natural experiment. Teaching loads are standardized via allocation by the school's administration; individuals have a well-defined area of practice and a workload procedural document that codifies teaching expectations (with regard to both quality and quantity) regardless of promotion and tenure. Thus, focusing solely on research productivity does not automatically bias the results should faculty become less productive post tenure and/or promotion in their teaching and service activities. Second, this school contains a relatively even mix of tenure-track and nontenure track faculty, and a broad array of clinical and social scientists. The school of pharmacy also clearly delineates tenure and promotion as distinct processes. Tenure-eligible faculty may be hired at the associate professor rank, but without tenure (which may be earned on a compact time frame). Non-tenuretrack faculty have a system that allows promotion through the assistant, associate, and full professor ranks on a timeline that approximately parallels the system available for tenure-eligible faculty. A process also exists that, given budgetary approval, allows non-tenure-track faculty to convert to tenure-eligible positions. These factors are important, because they allow a degree of comparability across different departments and faculty appointments within the school of pharmacy.

\section{Study design}

The study design is primarily descriptive in nature since this is a single site evaluation. Starting in 2008 , information on the type of position, academic rank, and scholarly productivity was collected for all faculty employed in the school of pharmacy. If faculty left the school (resignation, retirement), this information was not included in the tables, as were the start dates for faculty hired after 2008. Thus, the study's design is balanced in its evaluation process, as all faculty are available for assessment over the entire study evaluation period. Information was 
collected through the end of the 2017 calendar year. This provides a sufficient time span to ensure that dramatic productivity increases or decreases "average out," thereby providing a reasonably reliable measure of scholarly output.

Scholarly output has two components: the "quantity" of output and/or productivity, and the "quality" of scholarly work. Because quality is inherently difficult to characterize, and given the paucity of research in this area, a decision was made to focus on the quantity of scholarly output, in particular refereed publications, book chapters, and non-refereed publications. The study's authors collected the following: 1) the number of publications and grants (as PI, Co-PI or Co-l) at the time of application for promotion; 2) the number publications and grants through December 31, 2017 for the promoted faculty; and 3 ) the comparison of rates in \#1 and \#2. This information, while admittedly imperfect, is consistent with how this school of pharmacy, as well as the pharmacy literature, characterize the quantity of scholarship. ${ }^{11}$ This information is reported as mean values to ensure that these metrics can be interpreted in a reliable fashion and to facilitate meaningful comparisons over time (i.e. to ensure that idiosyncrasies in the data "average out" over time and/or across faculty). Information was gleaned using the promotion and tenure documents (or "portfolios") submitted by faculty at the school of pharmacy. As per university promotion policy requirements, the candidate prepares and submits a portfolio on August 15 of the year they submit for promotion and or tenure. Portfolios were examined from 2008 through the end of 2017 (the most recent calendar year available at the time the study was conducted) and the tabulation of publications and grants were confirmed based on portfolio assessment that was retrospective in nature. From the time of application for promotion to the end of the study period, each faculty member was also requested (by cover letter) to provide an updated list of publications and grants. This aspect of the study was prospective in nature and $100 \%$ of the faculty responded to this request. The number of faculty and each rank were compared at the time of application for promotion and since promotion for the respective years, through the end of 2017.

Because the study's experimental design is observational and limited to a single institution, any data collected are unlikely to meet the assumptions necessary for hypothesis testing and advanced forms of statistical analysis. Hence, all results are descriptive, and focus on frequencies, means, and other relevant descriptive statistics. The procedures were approved as an exempt review by the university Institutional Review Committee.

Results

The socio-demographic characteristics of the promoted faculty sample is comprised of both pharmacy practice and pharmaceutical sciences faculty members. In 2008, in pharmacy practice there were two full professors with tenure, two associate professors with tenure, and seven assistant professors of practice (non-tenure track), and by the end of 2017, this increased to five full professors (3 Ph.D. and 2 Pharm.D. degrees) with tenure (one in an administrative position), one associate professor with tenure in an administrative position, seven associate professors without tenure (non-tenure track, Pharm.D.), and seven assistant professors of practice (nontenure track). In pharmaceutical sciences, there were three full professors with tenure, one associate professor with tenure, and four assistant professors (tenure track) in 2008. This increased in 2017 to three full professors with tenure (Ph.D.), five associate professors with tenure (Ph.D.), and two assistant professors (tenure track, Ph.D.).

The number of publications is reported at promotion and those post-promotion (Table 1). The average number of total publications for associate professor (non-tenure track) for pharmacy practice was 6.8 and for pharmaceutical sciences was 29.8. Since promotion to associate professors, the average number of total publications for pharmacy practice was 4.2 and for pharmaceutical sciences was 16.2. At the time of promotion to associate professor, mean numbers of total publications per year for faculty housed in the pharmacy practice department were 1.1 and 1.4 for post-promotion. For pharmaceutical sciences department faculty, corresponding means were 5.0 and 4.1, respectively. Overall, the means for associate professors (non-tenure track) increased for pharmacy practice faculty and decreased for pharmaceutical sciences faculty.

At the time of promotion, the average number of total publications for full professor for pharmacy practice was 65 , and for pharmaceutical sciences was 38.5. Full professors in pharmacy practice have averaged total publications was 45.3 and for pharmaceutical sciences was 37.5. At the time of promotion to full professor, the mean numbers of total publications per year for pharmacy practice faculty were 7.0 and 7.2 for post-promotion. For pharmaceutical sciences faculty, corresponding means were 3.5 and 4.7 , respectively. Overall, the means for full professors increased for pharmacy practice faculty and decreased for pharmaceutical sciences faculty.

Grant activity is also summarized at time of promotion and since the time of promotion (Table 2). At the time of promotion, the average number of funded grants for associate professor (nontenure track) for pharmacy practice was 4.0 for a total of $\$ 55,342$ $[\$ 13,118$ (Principal Investigator or $\mathrm{PI})]$ and for pharmaceutical sciences was 3.5 grants totaling $\$ 998,039[\$ 692,255]$.

Post-Promotion, the average number of funded grants for associate professors of pharmacy practice was 8.0, for a total of $\$ 153,570[\$ 41,715$ (PI)]. For pharmaceutical sciences, the associate professor faculty the average was 2.3 grants for a total of $\$ 755,744$ [\$572,369 (PI)]. For grant activity, associate professors and full professors increased the mean total dollars per year from pre-promotion to post-promotion for both pharmacy practice and pharmaceutical sciences. 
At the time of promotion for full professor for pharmacy practice, the average number of grants was 11.0 and average funding was $\$ 718,578[\$ 235,474$ (PI)]. Pharmaceutical sciences faculty averaged 3 grants with $\$ 3,536,777$ in funding $[\$ 2,619,757$ $(\mathrm{PI})]$. At post-promotion, the average number of funded grants for full professors of pharmacy practice was 11.0 for a total of $\$ 1,767,124[\$ 452,148(\mathrm{PI})]$. Pharmaceutical sciences faculty was 7 grants, on average, for a total of $\$ 9,474,875[\$ 9,198,875$ (PI)]. For grant activity, the full professors for both pharmacy practice and pharmaceutical sciences increased the mean total dollars per year from pre-promotion to post-promotion.

\section{Discussion}

A common perception in academia is that once faculty are promoted they lose their drive in pursuing scholarship as evidenced by a decrease in their pursuit of scholarship..$^{4-6}$ This may lead to a decrease in productivity in publications and grants funded. Alternatively, the evidence from this public university school of pharmacy suggests that this perception is inaccurate. Since the time of application for promotion, for both pharmacy practice and pharmaceutical sciences, and with only two exceptions (the associate professor category in pharmaceutical sciences and one associate professor with tenure in pharmacy practice), scholarly productivity is maintained or improved since the time of promotion. This is especially true for full professors, whose productivity is maintained or improved since the time of promotion to that rank. The research productivity is particularly high for three full professors in pharmacy practice, who are in the social and administrative sciences. While this university was classified in the Weathers and Unni 2018 study as a nonintensive research university, the productivity both before and after promotion were higher than the 0.92 average publications per year national rate. ${ }^{10}$ Similarly, the publication rates for pharmaceutical sciences was substantially higher than the 0.82 national average. ${ }^{10,14}$ Some of this research productivity is due to increased collaboration with junior faculty. Our research supports studies in other professional fields (specifically business), suggesting that tenure and promotion may actually enhance scholarship over the course of one's career. ${ }^{5,15}$

Arguments against tenure (and, to a lesser extent, promotion) are based on both an assumption and the concept of economic efficiency. The assumption is that, within the context of tenure as a means to ensure academic freedom, faculty, once tenured and assured of employment protection, reduce their research efforts. This, in turn, reduces the production of academic knowledge, and the efficiency of the institution as a whole. Conversely, faculty who are prestige-seeking, who want to maintain employment mobility, and those who align (some or all of) their personal identities with their professional responsibilities may find incentives over and above promotion and/or tenure to remain productive scholars. This study's findings are consistent with the latter.

However, the truth may lie somewhere between these two positions. At least one study found no significant differences in research productivity by rank and tenure status; however there was an association between research productivity and length of service with an institution. ${ }^{15}$ Faculty who (regardless of rank) had been employed at the institution for more than 20 years were less productive researchers. This suggests that the literature has failed to resolve this policy issue because it has measured the wrong factors that incentivize faculty scholarly productivity. Instead, policies targeting lifelong faculty development may be more effective if they focus on these other factors (including length of service), rather than academic rank and tenure status. ${ }^{16}$ In our study, only one faculty member in pharmaceutical sciences has been employed for more than 20 years at this institution. All the other participating faculty in both departments have been employed for less than 20 years. Empowerment, training in research skills, travel funding incentives, and invitations to participate in collaborative research projects are seen as more powerful incentives to conduct, present and publish research.

We did not collect information about teaching loads, but other responsibilities significantly impact distribution of effort and regularly occur following promotion. These more senior faculty sometimes take on formal leadership/administrative roles, are tasked with leading large initiatives (e.g., curriculum re-design, policy changes, etc.), and committee leadership, among other duties. It is acknowledge that a faculty member's position responsibilities may change following promotion. In this study, two faculty (associate professor with tenure and a full professor) were affected by this, and were promoted to associate deans and this may have affected their scholarship. Inherently, these larger roles may impact scholarly productivity. It could be that maintaining a consistent publication record in light of additional leadership responsibilities actually represents more efficient and perhaps greater productivity in publishing and securing grants given their distribution of effort. These responsibilities, at least at the highest/most formal levels, must be addressed in the cohort of faculty evaluated here, and discussion of the senior faculty's changing roles is imperative. At this institution, promoted faculty are encouraged by administration to assume increased mentoring roles for new and junior level faculty. Nonetheless, faculty workload is balanced by administration to account for focused adjustments to contributions related to teaching, service, and scholarship.

Infrastructure at this school of pharmacy may contribute to continued productivity of senior and junior, level faculty. There are regularly scheduled huddles for faculty to discuss their current ideas for research projects; this provides a natural avenue for research design improvement. Additionally, there is an annual research development series conducted by senior faculty in the school. Instead of a formal mentorship program, the school uses an informal mentoring process where senior faculty are encouraged to mentor new faculty and to involve them in their research/scholarship projects. This informal mentorship process has produced collaborations that have been successful in the areas of grantsmanship and other scholarly 
output. Administration has ongoing expectations for scholarly productivity. Each department conducts annual performance reviews where each faculty member completes a faculty annual evaluation form that reviews teaching activity (e.g. didactic, experiential, advising, innovative method of delivery or assessment, self-development activities for teaching); research/scholarly activities (e.g. peer-reviewed publications, book chapters, poster or podium presentations, grants proposals, IRB protocol submissions, and self-development activities for scholarship); and service activities (e.g. professional associations, departmental, college and university committees, reviewers of journal articles, service awards/recognitions, selfdevelopment activities for service). The department chair rates each of the three activities on a 4-point scale from significant improvement needed to exceeds performance standard.

Investigators have examined the publications in colleges and/or schools of pharmacy, subdivided the publications by pharmaceutical sciences and by pharmacy practice, and further by research-intensive and non-intensive universities. Additional work should be continued in these areas, but also the type of research performed in this study should be conducted to further establish benchmarks of performance for scholarship.

A researcher's publishing career is generally determined by the date of the first publication in a particular database to the time of the current literature search. Benchmarking is becoming an important tool for colleges and schools of pharmacy as they collect and evaluate assessment data. ${ }^{17-19}$ At research-intensive universities, in a given year, $6 \%$ of all pharmaceutical sciences faculty members had more than 10 publications and $22 \%$ had zero publications. Analogous data by academic title include assistant professor, 22\%; associate professor, 26\%; and professor, $20 \%$. Overall, $15 \%$ of all faculty members published $50 \%$ of all the publications. Average author productivity was highest for pharmaceutics at 10.9 [(95\% confidence level $(\mathrm{Cl})$, 8.0-13.8)], pharmacology at $6.0(95 \% \mathrm{Cl}, 4.8-7.3)$, and social and administrative sciences at $2.6(95 \% \mathrm{Cl}, 1.5-3.7)$. About two thirds $(67 \%)$ of total publications were articles, and $19 \%$ were abstracts, $6 \%$ reviews, $4 \%$ proceedings, $2 \%$ editorials, $1 \%$ letters, and $1 \%$ other publications). ${ }^{12}$ Despite the increase in number of publications, this contribution was at a rate of less than one publication per faculty member per year suggesting that a limited number of faculty members produced the majority of publications. Using the findings of our study as a benchmark, and continuing to update the findings periodically, may facilitate the development and assessment of strategies to engage more pharmacy faculty members in the publication process. ${ }^{14}$

This study presumes that the PTE process is both transparent and implemented appropriately and consistently. In the shortrun, faculty should be aware of the formal and informal requirements to be tenure and/or promoted, and they may choose to direct their efforts towards what they perceive those requirements to be, and away from activities that do not "count" favorably or meaningfully towards tenure and/or promotion. In the long-run, faculty at this institution may choose to revise promotion and tenure documents, as well as to develop a comprehensive set of benchmarks, to ensure that what should be "counted," counts appropriately towards promotion and tenure. While the focus of this research is on scholarship, the authors emphasize that such activities should also be conducted for other areas of evaluation (including teaching, service and clinical practice). The authors acknowledge that service and teaching responsibilities may impact scholarly productivity, especially if they do not remain static or not allocated consistently across faculty, and were not quantified in this study. Indeed, some faculty (post promotion and/or tenure) intentionally shift the relative balance of their time towards teaching or service (or both) at the expense of research. Some of these shifts may be a direct reflection of the faculty's interests, while others may reflect a faculty member's sense of obligation to protect junior faculty from higher teaching and service loads. Other institutions intentionally ask faculty to undertake greater teaching and service activities while maintaining expectations for scholarship. In such cases, faculty are expected to offset these additional time commitments by gaining efficiencies in research and/or teaching, or by pursuing different areas of scholarly inquiry. In any of these cases, if the PTE process is not transparent, or if faculty are unaware of certain requirements, the information that they report will be less relevant to the actual rationale for the awarding of tenure and/or promotion. In such cases, the results of this study (which are drawn from faculty PTE portfolios) will be biased.

\section{Limitations}

One important limitation of this study is the self-reported nature of the data. The number of publications and grants are compiled by the faculty member seeking tenure and/or promotion, then are rigorously reviewed by each level of the PTE process. If requested, the faculty member was asked to provide more information concerning their stated documents. Most faculty members include representative publications in their submitted supplementary materials. However, the actual number of publications or grants since promotion was not verified by the investigators and may be subjected to self-reporting errors. We note in passing that, while inaccurate self-reported information may exist in the data, these types of biases are likely to be limited in nature. All promotion and tenure packets and annual review information in this school of pharmacy are a part of open records. Thus, faculty are aware that self-reported data could be verified, and interested parties could question discrepancies in self-reported data.

A second limitation is the use of mean publications, mean grants, and mean grant dollars, as key indicators of the quantity of scholarly output. The number of scholarly publications may be confounded by faculty who wait different lengths of time before pursuing promotion. Scholarly publications may also be confounded in instances where faculty submit manuscripts during the promotion and tenure process, but which are accepted and/or published after the promotion and/or tenure 
process is complete. The quantity of grants, as well as the amount of grant funding, is especially problematic as a measure of the quantity of scholarly output. There are two major confounding issues with grants. The first is that grants are used to fund research, and are actually inputs, not outputs, of the research process. Because inflows of funds do not automatically and obviously translate into specific outputs, they are imperfect measures of long-term research productivity. Second, a single grant application may lead to multiple years of funding. Some grants may be disbursed over multiple years, but may front or back load payments, depending on the research team's capital equipment needs, or research design considerations. Some grants have "train the trainer," infrastructure development, or outreach components. In all of these scenarios, it is difficult to disentangle those funds directed towards scholarship in a given year and those to other purposes, or in other years. More insidiously, acceptance rates of major funding agencies (i.e., the $\mathrm{NIH}$ ) are typically around $10 \%$. So while a grant may be awarded in one year, it might take more than five years of previous scholarly productivity to amass the expertise to attain a major grant. Cumulatively, while our measures of the quantity of scholarly output are consistent with both the literature and this school of pharmacy's promotion and tenure process, they are inherently flawed. Future research is necessary to accurately define the quantity of scholarly output, as well as define valid and reliable empirical indicators of the quantity of scholarly output.

A third limitation is that this study is a small, retrospective, observational study over a fixed period of time at a public university school of pharmacy. It is unwise to generalize the study results to other geographic regions, or to colleges and/or schools of pharmacy whose institutional characteristics may differ widely from the one in this case study.

A final limitation is that the current study examines only the quantity of two main types of scholarly output. The quality of scholarly output is not addressed in this manuscript. Two aspects of the "quality" of scholarship are particularly important because they are used (whether explicitly or implicitly) in the promotion and/or tenure process. The first is a characterization of faculty's role in a scholarly work (whether measured as author seniority, author contribution to the manuscript, or the number of coauthors), or a grant application (principal investigator, coprincipal investigator, co-investigator, etc.). The second aspect of "quality" is the prestige of the output or funding source, whether measured as a journal ranking, impact factor, or inclusion in a major database (i.e., Web of Science). The characterizations are crucial, because they create incentives governing how faculty spend their time, and by extension characterize the body of a faculty's scholarly work at every stage of her/his career. Moreover, while various indicators of "quality" exist, little consensus exists in the literature about how these indicators are used in the promotion and tenure process. This, in turn, frames any future empirical evaluations of whether faculty scholarship is improved, maintained, or declined after promotion and/or tenure occurs. Once a more comprehensive measure of scholarly output (inclusive of quantity, quality, and secondary outputs) spillovers between scholarly output and other faculty duties, most notably didactic and experiential instruction must also be characterized.

\section{Conclusion}

The research productivity of the faculty at this school of pharmacy continues to be either maintained or increased since their promotion date for this group of faculty. This evidence runs counter to the prevailing belief that promotion and tenure leads to inactivity ("dead wood phenomena") that is typically considered prevalent at many universities. This is a small pilot study and is not considered generalizable to other universities. However, the methods described here may be used as a roadmap for other schools to assess their own productivity and subsequently make comparisons to national benchmarks. This type of assessment should be replicated by other schools of pharmacy to validate continued productivity of promoted/tenured faculty compared to benchmark expectations.

Acknowledgments: A presentation was made at the MBAA International Conference in Chicago, Illinois, April 18, 2018. The authors acknowledge and appreciate the support of the pharmacy faculty who participated in this study.

Conflict of interest: The authors report no conflict of interest in the conduction of this study or the preparation of this manuscript.

Financial Disclosures: The authors did not receive any funding to conduct this study.

\section{References}

1. Boyer EL. Scholarship Revisited: Priorities of the Professorate. Lawrenceville, NJ: Princeton University Press; 1990.

2. Smesny AL, Williams JS, Brazeau GA, Weber RJ, Matthews HW, Das SK. Barriers to scholarship in dentistry, medicine, nursing, and pharmacy practice faculty. Am J Pharm Educ. 2007;71(5):Article 91.

3. Jungnickel PW. Scholarly performance and related variables: a comparison of pharmacy practice faculty and departmental chairpersons. Am J Pharm Educ. 1997;61(1):34-44.

4. Premeaux SR. Tenure perspectives: tenured versus nontenured tenure-track faculty. J Educ Bus. 2012;87:121-127.

5. Chen Y, Gupta A, Hoshower L. Factors that motivate business faculty to conduct research: an expectancy theory analysis. J Educ Bus. 2006;81:179-189. 
6. Williams JA. Frustrated faculty struggle to defend tenure before it's too late. Chron High Educ. 2018;64(36):21.

7. Hnat HB, Mahony D, Fitzgerald S, Crawford F. Distributive justice and higher education resource allocation: perceptions of fairness. Innov High Educ. 2015;40:79-93.

8. Coleman $\mathrm{Cl}$, Schlesselman LS, Lao E, White CM. Number and impact of published scholarly works by pharmacy practice faculty members at accredited US colleges and schools of pharmacy (2001- 2003). Am J Pharm Educ. 2007;71(3):Article 44.

9. Chisholm-Burns MA, Spivey C, Martin JR, Wyles C, Ehrman C, Schlesselman LS. A 5-year analysis of peerreviewed journal article publications of pharmacy practice faculty members. Am J Pharm Educ. 2012;76(7):Article 127.

10. Weathers T, Unni E. Publication rates of social and administrative sciences pharmacy faculty in nonresearch intensive pharmacy schools. Am J Pharm Educ. 2018;82(3):Article 6229.

11. Thompson DF, Nahata MC. Pharmaceutical science faculty publication records at research-intensive pharmacy colleges and schools. Am J Pharm Educ. 2012;76(9):Article 173.

12. Schlesselman LS, Coleman Cl. College and school of pharmacy characteristics associated with US News and World Report Rankings. Am J Pharm Educ. 2013;77(3):Article 55.
13. Bloom TJ, Schlesselman L. Publication rates for pharmaceutical sciences faculty members at nonresearch-intensive US schools of pharmacy. Am J Pharm Educ. 2015; 79 (9) Article 136.

14. Thompson DF, Harrison KE. Basic science pharmacy faculty publication patterns from research-intensive US Colleges (1999- 2003). Pharm Educ. 2005;5(2):8386.

15. Tang TL, Chamberlain M. Effects of rank, tenure, length of service, and institution on faculty attitudes toward research and teaching: the case of regional state universities. J Educ Bus. 2003;78:103-110.

16. Williams A, Most professors hate post-tenure review. A better approach might look like this. Chron High Educ. 2018;64(23):1.

17. Bosso JA, Chisholm-Burns M, Nappi J, Gubbins PO, Ross LA. Benchmarking in academic pharmacy departments. Am J Pharm Educ. 2010;74(8):Article 140.

18. Thompson DF, Callen EC, Nahata MC. New indices in scholarship assessment. Am J Pharm Educ. 2009;73(6):Article 111.

19. Thompson DF, Callen EC, Nahata MC. Publication metrics and record of pharmacy practice chairs. Ann Pharmacother. 2009; 43(2):268-275. 
Table 1: Mean publications pre- and post-promotion

$\begin{array}{lcccc} & & \text { Publications/faculty } & \text { Publications/faculty } \\ \text { Position applied to: } & \text { Gender } & \begin{array}{c}\text { member/per year } \\ \text { member/per year }\end{array} & \text { Post-promotion (mean) }\end{array}$

Panel A: Department of Pharmacy Practice

Full Professor (tenure) $(n=3)$

Associate (tenure) $(n=1)$

1

0.4

Associate (non-tenure) $(n=6)$

2

4

1.1

1.4

Panel B: Department of Pharmaceutical Sciences

Full Professor (tenure) $(n=2)$

2

3.5

4.7

Associate (tenure) $(n=4)$

3

1

5

4.1

Table 2: Mean grant dollars awarded pre- and post-promotion

Position applied to:

Gender
\# male \# female

1

4

2

2

Full Professor (tenure) $(n=2)$

Associate (tenure) $(n=4)$

Associate (tenure) $(n=1)$

7,000

Associate (non-tenure) $(n=6)$

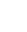

55,342

Panel B: Department of Pharmaceutical Sciences

$3,536,777$

1

692,255
718,578

3

Grants/faculty member/per year Pre-promotion (mean)
Grants/faculty member/per year Post-promotion (mean)

Panel A: Department of Pharmacy Practice

73,500

153,570

$9,424,375$

755,744 